\title{
KLÂSİK TÜRK ŞİiRİNDE ŞARKI VE İLK ÖRNEKLER
}

\section{Rasih ERKUL $^{1}$}

\begin{abstract}
ÖZ
Her milletin edebiyatındaki ilk nazım şekilleri, zamanla gelişme ve değisşiklikler gösterse de, doğrudan doğruya kendi millî dehasının bir verimidir. Bu şekiller, etkilerini daha sonraki devirlerde de hissettirir. Türk şiir geleneğinin ve zevkinin doğurduğu millî nazım şekli olarak yalnız Türk edebiyatında görülen şarkı, divan şiirindeki millî motif boyutunun bir yönünü ortaya koyar.

Eski Türk nazım şeklinin dörtlükleri, İslâmî devir Türk edebiyatının gelișmesinde etkili rol oynar. Klâsik șiirin nazım șekillerinden biri şarkıdır. Klâsik Türk edebiyatında, divanında, şarkı ismini taşıyan şiirlere yer veren ilk şair Nấilì'dir. Onun şarkıları, çağında türünün ilk ve en güzel örnekleri kabul edilirken, dilinin sadeliğiyle de dikkat çeker. Şair, devrine göre anlaşılır bir dil kullanmayı tercih eder.

Türk şiir geleneğinin ve zevkinin doğurduğu millî nazım şekli olarak yalnız Türk edebiyatında görülen şarkı, divan șiirindeki millî motif boyutunun bir yönünü ortaya koyar. Bu çalışmada, divan şiirinin son dönemlerinde, gazelden sonra en yaygın ve popüler şiir olan şarkının kaynağı ve ilk örnekleri üzerinde durulacaktır.
\end{abstract}

Anahtar Kelimeler: Divan şiiri, Şiir dili, Şarkı, Nâ'ilî.

\section{SONG IN TURKISH CLASSIC POETRY AND ITS FIRST EXAMPLES}

\begin{abstract}
The first verse types in the literature of every nation change and develop over time, and they are direct products of their national prodigy. These forms make their effects felt in subsequent periods as well. Song, derived from Turkish poetic traditions and tastes, and seen only in Turkish literature as the national verse form, illustrates one dimension of national motif in divan poetry.

The quatrains of old Turkish verse type play an important role in the development of the Islamic-era Turkish literature. One of the verse types of classical poetry is song. The first poet to use song in classical Turkish literature and divan was Nâ'ilî. His songs are accepted as the first and most beautiful examples of this type in his era and are distinguished by the plain language he used, relatively simple compared to others in his era.
\end{abstract}

1 Yrd. Doç. Dr., Celal Bayar Üniversitesi, Demirci Eğitim Fakültesi, Türkçe Eğitimi Bölümü, rasiherkul@hotmail.com. 
Song, derived from Turkish poetic traditions and tastes, and seen only in Turkish literature as the national verse form, illustrates one dimension of national motif in divan poetry. In this study, we will elaborate on the source and first examples of song which was the most popular and widespread type of poetry after the lyric poem (gazel) in the late periods of divan poetry.

Keywords: Ottoman Divan poetry, Poem language, Song, Na'ilî.

\section{Giriş}

Her milletin edebiyatında görülen ilk nazım şekilleri, doğrudan doğruya kendi millî dehasının bir verimidir. Bu şekiller, daha sonraları çeşitli dış sebeplerle değişiklik /gelişme gösterse bile, etkilerini daha sonraki devirlerde de hissettirir. İslâmî devir Türk edebiyatında, ortak kültürün içinde yer alan Arap ve İran edebiyatlarının nazım şekilleri benimsenip kullanılırken, yeni şiir tarzına, Türk şiir geleneğinin ilk nazım şekilleri de girer. Dörtlük veya dörtlük birimleri formundaki bu şiirler, millî ve tarihî zevkin birer devamı olan şiirlerdir.

Eski Türk nazım şeklinin dörtlükleri, İslâmî devir Türk edebiyatının gelişmesinde etkili rol oynar. Diğer İslâmî edebiyatlarda bulunmayıp sadece Türk klâsik şiirinde görülen nazım şekilleri, bunların eski Türk şiirinin bir devamı olduğunun bir delilidir. Klâsik şiirin tamamen bir taklitten ibaret olmadığını da gösteren bu nazım şekillerinden biri şarkıdır.

Batı etkisinde gelişen Türk edebiyatı devirlerinde de görülen şarkl, ilk örneklerinden itibaren daha popüler bir hâl almış, mûsikî eşliğinde çok söylenen ve dinlenilen bir şiir tarzı olmuştur. $\mathrm{Bu}$ çalışmada, divan şiirinin son dönemlerinde, gazel tarzından sonra en yaygın ve popüler şiir çeşidi olan şarkının kaynağı ve Nâ'ilî́deki örnekleri üzerinde durulacaktır.

\section{Türk Şiirinde Şarkı}

Türk edebiyatında doğan (Dilçin, 1983:214) şarkı, halk edebiyatındaki "türkü"nün karşılığı olarak gösterilir. (İpekten, 1985:115). Halk şiirinin, ezgi ile söylenen her çeşidine türkü denir. Fuat Köprülü'nün “ Türklere mahsus bir beste ile söylenen halk şarkılarıdır", Ahmet Talât Onay'ın da " Türklere mahsus lahin ile söylenen şarkılardır" diye tanımladığı türkü terimi, Türk kelimesinin sonuna nispet eki getirilerek elde edilen Türkînnin zamanla değişmesiyle ortaya çıkmıştır. (Köprülü, 1984, Onay, 2000' den aktaran Dizdaroğlu, 1969:102) "Şarkı, deyiş, hava, deme, ağıt, ninni” kavramları da, "türkü" yerine kullanılır. 
Türkü, halk şiirinin en eski türlerinden biridir. 15. yüzyıl başlarında Horasan'da ilk örneği ortaya çlkan "türkü"nün Anadolu Türk Edebiyatındaki en eski örnekleri, 16. yüzyıldan öteye geçmez. Biçim bakımından türkü olan ilk metni Öksüz Baba verir. Bu, duraksız sekizli hece ölçüsü kalıbındaki türkünün bilinen en eski örneğidir. ( Köprülü, 1940:37-38)

\section{O Alaşar dağı kırda \\ Davşan neler eder kurda}

Türkünün en büyük ayrımı, ezgisindedir. Mani ve koşma tipindeki şiirler, ezgilerinin değişmesiyle türkü olur (Dizdaroğlu,1969:103). Yakıcılarının (söyleyenlerinin) bilinmemesi, anonim nitelik Türkü'yü diğer türlerden ayıran özelliklerden biridir. Ayrıca bir saz şairinin söylediği bir şiir sonradan bir türkü olabilir.

Halk şiiri türlerinin her biri türkü olabileceğinden türkülerin yapısı, çok değişiktir. Sözden çok ezgiyle ilişkili olmasından dolayı türküler, hece ölçüsünün her kalıbıyla söylenir. En çok görülenler şunlardır: Bentleri iki, üç mısradan kurulu türküler, dörtlüklerden kurulu mani ve koşma tipi) türküler, bağlamalı türküler. (Dizdaroğlu, 1969:107-109)

Halk şairleri, aruzlu şiirlerin özel ezgilerle okunmasından ötürü aruz kalıplarına uygun şiirler yazmışlardır. Okuryazar olan saz şairlerinin yanı sıra ümmî saz şairleri de arz kalıplarına başvurmuşlardır. Divan, selîs, semaî, kalenderî, satranç, vezn-i âher gibi.

Türkü ile ilgili tanımlarda, "...Türklere has bir biçimde şarkı, daha çok şarkı” olarak onun, ezgiyle söylendiği ifade edilir. (Temel Türkçe Sözlük,1986:1397-1398, Onay, 2000:33)) Böylece mani ve koşma tipindeki şiirler olan 'türkü’nün, en önemli özelliğinin ezgiyle söylenmesi olduğu ortaya çıkar. Bir ezgiyle söylenen her türlü manzum parça halkça türkü kabul edilirken, "Eski mecmualarda Divan şiirinin murabba'ları hatta gazelleri bile türkü başlığı ile" kaydedilir. (Köprülü, 1984:275) Ali Şir Nevâî'nin Mîzânü'l-Evzân'ına göre eski "koşuk" tarzı, Sultan Hüseyin Mirza zamanında değişime uğrayarak "türkü" adını alır, ona vezin tahsis edilir, saraylarda fevkalâde büyük rağbet kazanır, bu tarzdaki eserlerle şöhret kazananlara da türkî-gûy lâkabı verilir. (Köprülü, 2004:212) Buna göre türkü adlı ilk parçaların XV. yüzyıl başlarında Çağatay edebiyatında Doğu Türklerince kullanıldığı görülür. Anadolu sahası 
Türk edebiyatında ise, XVI. yüzyıldan öteye çıkmayan türkünün, şekil bakımından ilk örneğini Öksüz Dede verir. (Köprülü, 1940:37-38)

\author{
Gül budanmış dal dal olmuş, \\ Menekșesi yol yol olmuş \\ Siyah zülfün tel tel olmuş \\ Biz bu yerlerden gideli, \\ Gurbet illere düșeli
}

XV. ve XVI. yüzyıl şairlerinin divanlarında bestelenmek üzere yazılan, daha sonraları şekil ve konu yönüyle şarkı olarak isimlendirilecek olan pek çok murabba görülür. (İpekten,1985:115) Aynı vezinde, dörder misralık bendlerin birleşmesiyle oluşan musammatlardan murabbalar, öteden beri kullanılagelen şekillerdir. Murabbada, bendlerin son mısraları sadece kafiyeyle bağlandığı gibi (aaaa - bbba), aynen de tekrarlanabilir (aaaA-bbbA). Bu kafiye düzenleri, murabbanın klâsik şekilleridir. (İpekten, 1985:110, Dilçin,1983: 212)

Murabbaın tanınmış örnekleri XV. yüzyılda Ahmet Paşa'nın sanat çevresinde toplanan şairler tarafından verilir. Melihî'nin "gönül" redifli murabbal, nazire geleneği içerisinde diğer şiirlerin söylenmesine yol açar. Bunlar, şarkı diye anılacak şiirlerin, murabba adıyla başladığını, bu tarz şiirlere murabba yerine şarkı denilmiş olabileceğini gösteren örneklerdir. Fakat bu tür şiirlerin "şarkı" adıyla Türk edebiyatında şiir ve mûsikî çığırı açacak şiirlere yol açması, sonraki yüzyılları bekler. (Banarlı, 1971: 204, Alpaslan, 1987: 14)

Şarkıyı edebî bir tür olarak kabul eden Halil Erdoğan Cengiz, Ubeydî'nin "şarkı" adlı iki şiirinin daha sonraki divanlarda görülen aynı adlı şiirlere benzemediğini göz önünde bulundurarak bu sonuca varır. Ona göre şarkı, bestelenmek üzere kaleme alınan veya bestelenen şiirlerin genel adıdır. (Cengiz, 1986:291-430)

XV. ve XVI. yüzyıl şairlerinin divanlarında, şarkı yerine bestelenmek üzere yazılmış murabbalar vardır. "Murabba bağlama" şarkı bestelemek anlamında kullanılmıştır. (Uysal, 1997:163) Bestelenmek üzere yazılan mütekerrir murabbalar, ilk bendlerinin kafiyelenişiyle kısmen şarkıdan ayrılır. (Pala, 199: 367) Kendi çapraz kafiye düzeniyle (abab cccb dddb), klâsik murabba şekillerinden ayrılan ve "şarkı" diye isimlendirilen şiirler XVII. yüzyılda görülmeye başlanır. Şarkının birinci dörtlügü̈ndeki mısralar, birbiriyle kafiyeli olabileceği gibi (aaaa) farklılık da (abab) gösterebilir. 
Murabbada olduğu gibi şarkının da bir temel kafiyesi vardır. $\mathrm{Bu}$ kafiyeye, her dörtlügün son mısraında tekrar edilir. Şarkının birinci dörtlüğündeki ikinci mısra, hiç değiştirilmeden öteki dörtlüklerin son mısraları olarak tekrar edilirse "nakarat" adını alır. Şarkılar bestelenmek için yazıldığı için dörtlük sayıları azdır. En fazla beş dörtlük halinde yazılmıştır. (Dilçin, 1983:214)

Şarkılarda kafiye düzeni, oldukça değişiktir. Dört mısralık bendlerle söylenmiş şarkı kafiyeleri şöyledir:

$\begin{array}{llll}\text { 1. Çapraz kafiyeli şarkı: } & \text { a b a b } & \text { c c c b } & \text { d d d b } \\ \text { 2. Nakaratlı çapraz kafiyeli şarkı: } & \text { a A a A } & \text { b b b A } & \text { c c c A } \\ & \text { a B a B } & \text { c c c B } & \text { d d d B }\end{array}$

Çapraz kafiyeli şarkılar dişındaki murabba, muhammes ve müseddes şarkılar, şekil ve kafiyeleri açısından bu nazım şekillerinin aynısıdır. Şarkıları bunlardan ayıran en önemli özellik, konularıdır. Şarkıların konuları çok az görülen birkaç örnek dışında yalnızca aşk ve sevgilinin güzelliğinin anlatılmasıdır. Öteki şekillerde hemen her konu işlenir. Şarkıların ikinci özelliği özellikle bestelendikleri için sade bir dille yazılmalarıdır. Murabba, muhammes ve müseddesler 16-18 bendi bulurken şarkıların bend sayısı az olup 3-5 arasındadır.

\section{Klâsik Türk Şiirinde Şarkı}

Divanının sonunda heceyle yazdığı şiirlerini "Fi't-türkiyyât" başlığı altında toplu olarak veren Karaovalı Zaîfî (ö. 1555- ?)nin şiirlerinin bir kısmının başındaki "der-makâm-ı rast; der-makâm-ı hüseynî" ifadelerinden bunların aynı zamanda bestelenmiş oldukları anlaşılır. "Murabba bağlamak" ifadesinin beste yapmak anlamında kullanıldığı düşünüldügünde, Türk edebiyatında "XVII. yüzyılda görülmeye başlayan şarkı nazım şeklini de belki daha erken çağlara indirmek mümkün olacaktır." (İsen, 1997:406) Daha önceki dönemlerde bestelenmek üzere yazılan "mütekerrir murabbalar" ise ilk bendlerinin kafiyelenişi yönünden kısmen şarkıdan ayrılır.

Türk Edebiyatında her bakımdan şarkı formuna uyan ilk şiirleri Nâilî (ö. 1666) yazmıştır. Nâ'ilî Divanı'nda 2/5 bend arasında 11 şarkı vardır. Şarkılar, konuşma diline yerleşenlerin dışında hemen hiç yabancı kelime ve tamlama kullanılmadan, türkülerde olduğu gibi sade bir Türkçe ile söylenmiştir. XVII. yüzyılın sonu ile XVIII. yüzyılın başında yaşayan, na't şairi olarak tanınan Yahya Nazîm (ö. 1727), 9 şarkı söylemiş ve şarkılarını kendisi bestelemiştir.

Divan edebiyatının en güzel şarkılarını Nedim (ö.1730), coşkulu ve neşeli yaradılışıyla kendini edebiyatımızın en usta şarkı şairi olarak kabul ettirmiştir. Nedim'in şarkılarının hepsi, daha kendi çağında bestelenmeye başlar ve günümüze kadar Türk sanat 
mûsikîsinin seçkin örnekler arasında yer alır. Ondan sonra şarkı yazanlar, onun şuhluğunu, coşkun söyleyişini ve yalın dilini örnek alırlar. Ancak Nedim, Türk edebiyatının en büyük şarkı yazarı olma unvanını daima korur. XVIII. yüzyılın sonunda Şeyh Galip (ö.1798)in 11 şarkısı vardır. Nâ'ilî̀nin şarkılarına yakın sadelikte yazılmış olan bu şarkılarda Nedim'in etkisi açıkça görülür.

XIX. yüzyılda şarkı yazan şair, çoğalır. Bu yüzyıl şairlerinin hemen hepsinin divanında bir veya birkaç şarkı vardır. Nedimin de etkisiyle şarkı konuları genişlerken muhammesten başka müseddes ve hatta gazel nazım şekliyle bile şarkılar söylendiği olur. Enderunlu Fazıl (ö.1810)ın, biri Nedim'i tazmin olmak üzere 4 müseddes ve 1 gazel şarkısı vardır Divan edebiyatında en çok şarkıyı Enderunlu Vasıf (ö.1824) yazmıștır. Pertev Paşa (ö.1837), Leyla Hanım (ö.1848), Fatin Efendi (ö.1866), Osman Nevres (ö.1876), Âsaf Mahmud Celâlettin Paşa (ö. 1903), Şeref Hanım (ö.1861) şarkılarıyla bașta gelen şairlerdir.

\section{Nâ'ilî-i Kadîm ve Şarkıları}

XVII. yüzyıl Klâsik Türk Edebiyatı'nın temsilcilerinden biri olan Nâ'ilî́nin (ö.1666) hayatı hakkında şair tezkireleri dışında muteber, ikinci bir kaynak yoktur (İpekten, 1999: 11). Şeyh ya da paşa olmadığı halde şiiriyle ön plâna çıkan Nâ'ilî’nin, edebî kişiliği bu açıdan önem arz etmektedir. Çünkü o, yalnızca sanatı ile kalıcılığı yakalamış, başarılı bir şairdir. Nâ'ilî̀nin şiiri söz konusu edildiğinde, onların yeni ve orijinal anlamlar içerdiği, kendine has bir vadide kaleme alınmış üslûp sahibi eserler olduğu düşüncesinde kaynakların hemfikir oldukları görülmektedir. (Şenödeyici, 2015)

Nâ'ilî, yabancı kelimeleri çok kullanır. Yabancı kelimelerle yapılan tamlamaların çokluğu ve uzunluğu, Nâtilî şiirinde dikkati çeker. Soyut kavram ifade eden kelimelerin, somut kavram ifade eden kelimelerle birleştirilerek tamlamalar yapılması ve bu tamlamaların sık kullanılması; Nấilî şiirinin en önemli özelliklerinden biridir. Nâ'ilî̀nin soyut kavramlı kelimelere çok yer vermesi ve bunları uzun tamlamalar, vasf-ı terkibîlerle birleștirmesi beyitte sözün kısalmasını sağlamıştır. Nâ'ilî́nin ağır ve sanatlı dilinin yanında, yalnız şarkılarında görülen sade bir dili de vardır (İpekten 1999: 88-95).

Manâ ve muhtevaya ait hemen hemen bütün özellikleri başarıyla kullanan şair, teşbih ve istiare mekanizmasındaki farklılıklar, ince hayaller ve yeni mazmunlar, hayal atlaması, tezat ve paradoks, mübalağa ve aşırı hayalcilik, ben dili, günlük tecrübeler, 
tabiat ve halk hikmetlerinden faydalanma ve önemli kavramlar ile imajlar konularında, özellikle başarılıdır (Babacan, 2010: 359)."

Türk edebiyatında, divanında, şarkı ismini taşıyan şiirlere yer veren ilk şair Nâ'ilî-i Kadîm (İpekten,1970: 486-494) Divanı'nda 2/5 bend arasında 11 şarkı vardır. Ortaya çıkışı belirlenemeyen (Cengiz,1986:317) bu şiirlerle ilgili olarak, Nâ'ilî’nin şarkıları, kafiye düzeniyle, klâsik murabba şekillerinden ayrılan ilk örneklerdir (İpekten, 1990:11)..

Arasında, çapraz kafiyeli, asıl türünün ilk örneği olan şiirlerin bulunduğu şarkıların özellikleri şöyle sıralanabilir:

1. Şarkıların bend sayısı, iki ile beș arasındadır. 1'i iki, 5'i üç, 2'si dört ve 4'ü de beş bendlidir. Şair, yedi değişik vezin kullandığı şarkılarında diğer şiirlerinde olduğu gibi, vezne hâkimdir. Bu durum, Nâ'ilì'nin özeliği yanında XVII. yüzyıl divan edebiyatının vezne hâkimiyetiyle de izah edilebilir.

2. Nâ'ilî̀nin diğer şiirlerinde görülen; "kafiyeden daha çok redifi tercih etme" durumu, şarkıları için de geçerlidir. Kafiyeyi ikinci sıraya alma, onun üslûbunun gereğidir. Redifler, daha çok kelime şeklinde kullanılmıștır.

Haste-i 'ş̧ka 'âfiyet demidür

Cân-ı meftûna 'âtıfet demidür

Dil-i mecrûha merhamet demidür

Döyemez intizâre sultânım （Nâ'ilî Divanı, 1970: 486)

"Aşk hastasına sağllk, hayran sevgiliye, yaralı gönle merhamet etme zamanıdır, Sultanım! Gönül sana bakmaya doyamaz."

Götürüp çehreden nikâbı yine

Eyle şermende âfitâbı yine

Pâymâl et dil-i harâbı yine

Salın ey nahl-ı bâğ-ı 'işve Salı (Nâ'ilî Divanı, 1970: 487)

"Gönlün siyah dumanından ter olarak düşüp gönle bakıp mahzun olma. Gönül ahının acısından ey cefa çektiren güzel kendini koru."

Ter düşüp dûd-ı siyâh-ı dilden

Olma âzûrde nigâh-ı dilden

Eser-i sûziş-i âh-ı dilden

Sakın ey şûh-ı cefâ-pîşe sakın (Nâ'ilî Divanı, 1970: 489) 
"Gönlün siyah dumanından ter olarak düşüp gönle bakıp mahzun olma. Gönül ahının acısından ey cefa çektiren güzel, kendini koru."

3. Şarkılar, kafiye düzeni bakımından üç değişik şekilde söylenmiştir. Ancak, esas kafiye düzeni, murabba olmakla beraber, birinci bendde, yeni bir düzenleme yapıldığı görülür: ( $a b a b-a A a A$ ve $\mathrm{aBaB}$ ) gibi. Buna rağmen, şarkıların yazıldığı tarihlerde, murabbaın yanı sıra "şarkı" adı verilen yeni bir nazım şeklinin bulunup bulunmadığı bilinmemektedir (Cengiz,1986:318). Şarkıların onunda birinci bendin son misral, diğer bendlerin dördüncü mısralarında aynen tekrarlanmıştır:

Yamandur hecr ile hâlüm

Bana yâr olmadun gitdün

Nedür cürmüm be hey zâlim

Bana yâr olmadun gitdün ～(Nâ'ilî Divanı, 1970: 488)

"Ayrılıkla halim yamandır. Bana yâr olmadı, gitti. Be hey zalim günahım nedir? Be hey zalim! Günahım nedir? Bana, yâr olmadın gittin.

Tutup dâmânunı ferdâ

Nigâhundan edüp șekvâ

Diyem mahșerde vâveylâ

Bana yâr olmadun gitdün

(Nâ'ilî Divanı, 1970: 488)

"Yarın eteğini tutup, bakışından şikâyet edip, mahşerde eyvah diyeyim; bana, yâr olmadın gittin."

Şarkılarından birinde ise, birinci bendin son mısraının, diğer bendlerin dördüncü mısralarında aynen tekrarlanmadığı görülür:

Sensüz olan 'iyş ü safâlar bize

Mâye-hûn-ı dil-i gam-hârdur

Sende güneh yok bu cefâlar bize

Hep eser-i baht-ı siyeh-kârdur

"Sensiz olan yaşama ve eğlenmeler bize, gönül kanı mayasının keder dikenidir. Sende günah yok, bu cefalar bize hep günahı çok talihimin yaptığı iştir." 

Âh yakar sîne-i nesrîn-veşün
Penbe ile yok oyunı âteşin
Bin var ise 'âşılk-ı hasret-keşün
Birisi de Nâ'ilî-i zârdur
(Nâ'ilî Divanı, 1970: 492)

"Pembe ile oyunu olmayan ateșin, yaban gülü gibi sine(mi) yakar. Hasret çeken bin(lerce) âşı̆̆ın (dan) birisi de acı çeken Nâ'iliî̀dir."

4. Şarkılarda, ahengin sağlanmasında önemli rol oynayan aliterasyonlar ve asonanslar dikkat çeker.

Gözedüp 'âşık-ı âvârelerün

Ele al gönlini dil-dâdelerün

Nazar et hâline üftâdelerün

İltifât eyle benüm sultânum (Nâ'ilî Divanı, 1970: 491)

"Âvâre âşılkları gözetip sana gönül verenlerin gönlünü al. Âşıkların haline bir bak, IIltifat et, sultanım."

Çok zamândur ki perîşânundur

Lâyık-ı şefkat ü ihsânundur

Dil-i mercûha ki kurbânundur

İltifât eyle benüm sultânum （Nâ'ilî Divanı, 1970: 491)

"Gönül çoktandır perişandır, iyilik ve șefkatine lâyıktır, yaralı gönül senin kurbanındır, iltifat et sultanım."

İlk dörtlükte "e" sesiyle asonans, ikinci dörtlükte de " $n$ " sesiyle aliterasyon sağlanmıştır.

XVII. yüzyıldan sonra da, murabbaların kafiye şekilleri kullanılıp, pek çok şarkı yazılır. Nâilî’nin;

Dönmiş rûh-ı zerdine çemen âşık-ı zârun

Bir gûne dahi 'âlemi var köhne bahârun

Feryâdı kafeslerde ciğer-sûz hezârun

Bir gûne dahi 'âlemi var köhne bahârun (Nâ'ilî Divanı, 1970: 493)

"İnleyen âşığın ruhu, yeșilden sarıya dönmüss, bu gidişle dahi bir köhne baharın dünyası var. Bülbülün kafeslerde ciğer yakan feryadı, bu 
$\overline{\text { gidișle dahi bir köhne baharın dünyası var." diyerek başlayan şarkısı, }}$ XVIII. yüzyllda Nedim,

Gül-zâr salın mevsimidir geşt ü güzârın

Ver hükmünü ey serv-i revân köhne bahârın

Dök zülfünü semmûr giyinsin ko izârın 1997: 254)

Ver hükmünü ey serv-i revân köhne bahârın (Nedim Divanı,

“Gezip dolaşma mevsimidir. Salına salına gül bahçesine git. Ey yürüyen servi, sonbaharın zevkini çıkar. Saçını dök de bırak yanağın samur giyinsin. Ey yürüyen servi, sonbaharın zevkini çıkar." (Mazıŏlu, 1988:184) diye başlayan şarkıyla tanzir edilir.

Şarkıya tabiî bir yakınlık duyan Nedim'in, bu tarzdaki başarısıyla ünlü bir şair olması (Mazıoğlu, 1988: 45) ve şarkının Nedim'in şiirleriyle rağbet kazanması, Şeyh Galib'in şarkı söylerken, Enderunlu Vâsıf'ın da Türk edebiyatında daha çok şarkı şairi olarak tanınması (Mazıoğlu, 1988: 71) konumuz dışında olmakla beraber, şarkı adına zikre değer gelişmelerdir.

5. Şarkıların muhtevasıyla, şairin diğer şiirleri arasında benzerlik görülür. Şair, şarkılarında da aşkı genellikle ayrılık, hüzün ve ıstırap yönüyle görür ve sıkıntılarını anlatır.

Dil ki müştâk-ı nâ-şikîbündür

Döyemez intizâra sultânım ～(Nấilî Divanı, 1970: 486)

“Gönül, sabırsız tutkunumdur, sana bakmaya doyamaz sultanım!”

Yamandur hecr ile hâlüm

Bana yâr olmadun gitdün

(Nâ'ilî Divanı, 1970: 488)

"Ayrılıkla halim yamandır, bana yar olmadın gittin."

'Âdu benzer nifâk etmiş

Bizümle yâr söyleșmez

(Nâ'ilî Divanı, 1970: 489)

"Düşman bir anlaşmazlık çıkarmış; yâr bizimle konuşmuyor."

Eser-i nâle-i şeb-gîrümden

Sakın ey şûh-ı cefâ-pîșe salkın

(Nâ'ilî Divanı, 1970: 489)

522 | Celal Bayar Üniversitesi Sosyal Bilimler Dergisi - Cilt: 14, Sayı: 1, Mart 2016 
"Seher vaktindeki inlememin tesirinden sakın, ey cefa çektiren sevgili sakın!"

Düșdi dil bir büt-i sitem-kâre

Yine geldük diyâr-ı hicrâne

(Nâ'ilî Divanı, 1970: 490)

“Gönül, sitem eden bir güzele düştü, yine ayrılık diyarına geldik."

Müştâkunum gel ey âfet-i cân

Ey bî-terahhum ey nâ-müselmân

(Nâ'ilî Divanı, 1970: 491)

"Senin tutkununum, ey merhametsiz, ey müslüman olmayan, ey can belâsı güzel gel."

Geçer firkat zamânı böyle kalmaz

Sağ olsun sevdüğüm Mevlâ kerimdür （Nâ'ilî Divanı, 1970:

"Ayrılık zamanı geçer, böyle kalmaz, Mevlâ kerimdir. Sevdiğim să̆ olsun."

Sensüz olan iyș ü safâlar bize

Mâye-i hûn-ı dil-i gam-hârdur

(Nâ'ilî Divanı, 1970: 492)

"Sensiz olan bayram ve safâlar bize, gönül kanının keder yiyenidir."

beyitleriyle başlayan şarkılarında, ıztıraplarını dile getiren şair,

Şecer-i Tur pây-mâlümdür

Salın ey nahl-ı bâğ-ı 'ișve salın

(Nâ'ilî Divanı,1970:487)

"Tur dağındaki ă̆aç, ayă̆ım altındadır, salın, ey naz bahçesinin süs ağacl, salın."

Dil-i nâ-kâma tegâfül besdür

İltifat eyle benüm sultânum

(Nâ'ilî Divanı,1970:490)

"Sultanım iltifat eyle, bahtsız gönle anlamazdan gelmen kâfidir." beyitleriyle başlayan şarkılarında, şuh bir edayla neşesini ifade eder. 


\section{Sonuç}

Şarkl, Türk şiir geleneğindeki “koşma” ve “türkü”lerin, divan şiirine etkisi ve şeklen bu gelenek içerisinde aruz vezniyle söylenmesinin bir devamıdır. Türk şiir geleneğinin ve zevkinin doğurduğu millî nazım şekli olarak yalnız Türk edebiyatında görülen şarkı, divan şiirindeki millî motif boyutunun bir yönünü ortaya koyar. Şarkı ile şarkının çıkış noktası kabul edilen murabba arasındaki farkı belirtecek ilk örnekler Nâ'ilî’de görülür.

Şiirlerine genel olarak tasavvufî konulara yer veren Nâ‘ilî̀nin şarkılarının teması aşk, sevgiliye duyulan özlem, sevgilinin acımasızlığı ve merhametsizliğidir. Şarkı dilinin, diğer şiirlerdeki dilden daha sade olması ve şarkının halk kitlelerinin anlayacağı dille yazılması gerektiği hususu hemen bütün şarkı yazan şairler tarafından uygulanmış olmakla beraber, Nâ'ilî’nin şarkılarındaki dil, daha farklıdır. Şair, șarkılarında "Bana yâr olmadın gittin, Nedir cürmüm be hey zalim!, Bizimle yâr söyleșmez, IIttifat eyle benüm sultanım, Yollarda kestin bizden selâmı, Geçer firkat zamanı böyle kalmaz." gibi söyleyişlerle devrine göre anlaşılır bir dil kullanmayı tercih eder. Bu dil, divanında yer alan diğer şiirlerindeki dilden çok farklı bir Türkçe'dir. Esasen, şairlerin üslûpta değişme ve yenileşmeyle, fazlalıklardan sıyrılmış, veciz ve olgun bir anlatıma yöneldiği bir zamanda, sadece eklerin Türkçe olduğu beyitleri oldukça fazla olan Nâ'ilı̀'nin şarkı dili, çağının dilinden de farklı bir özellik gösterir. Bu durum, şarkı dilinin diğer şiirlerdeki dilden daha sade olması ve şarkının halk kitlelerinin anlayacağı bir dille yazılması gerektiği benimseyișinin Nâ'ilî̀'de ulaștığı noktadır.

\section{KAYNAKLAR}

ALPASLAN, Ali (1987), Ahmet Paşa, Kültür ve Turizm Bakanlığı Yayınları, Ankara.

BABACAN, İsrafil (2010). Klâsik Şiirin Sonbaharı Sebk-i Hindî. Akçağ Yayınları, Ankara.

BANARLI, Nihat Sami(1971), Resimli Türk Edebiyatı Tarihi, Milli Eğitim Basımevi, İstanbul.

CENGİZ, Halil Erdoğan (1986), "Divan Şiirinde Musammatlar", Türk Dili, Sayı:451-415-417, Temmuz-Ağustos-Eylül

DílÇiN, Cem, (1983), Örneklerle Türk Şiir Bilgisi, Ankara.

Yayınları, Ankara.

DİZDAROĞLU, Hikmet (1969), Halk Şiirinde Türler, TDK

İPEKTEN, Haluk (1985), Eski Türk Edebiyatı-Nazım Şekilleri, Ankara. 
(1989), Enderunlu Vâsıf, Kültür ve Turizm

Bakanlığı Yayınları, Ankara.

(1999). Nâilî Hayatı, Edebî Kişiliği ve Bazı Şiirlerinin Açıklamaları, Akçağ Yayınları, Ankara.

.. (1990), Nâ'ilî Divanı, Akçağ Yayınları, Ankara.

İSEN, Mustafa(1997), "Divanlarda Heceyle Yazılmış Şiirler", Ötelerden Bir Ses, 1. Baskı, Akçağ Yayınları, Ankara.

KIRZIOĞLU, M. Fahrettin (!962), "Halk Edebiyatı Deyimlerimiz IV", Türk Dili, Sayı: 128, Mayıs

KÖPRÜLÜ, Fuad (1984), Türk Edebiyatında Illk Mutasavvıflar, Diyanet İşleri Başkanlığı Yayınları, Ankara.

Akçağ Yayınları, Ankara. (2004), "Tuyuğ", Edebiyat Araștırmaları 2, İstanbul (1940), Türk Saz Şairleri Antolojisi, C.II,

MAZIOĞLU, Hasibe (1988), Nedim, Kültür ve Turizm Bakanlığı Yayınları, Ankara.

Nedîm Divanı (1997), Hazırlayan: Muhsin Macit, Akçağ Yayınları, Ankara

Nâ'ilî-i Kadîm Divanı (1970), Edisyon Kritik, Haz. Haluk İpekten, Milli Eğitim Basımevi, İstanbul.

ONAY, Ahmet Talat (2000), Türk Halk Şirinin Şekil ve Nev'i, Haz. Cemal Kurnaz, Akçağ Yayınları, Ankara.

PALA, İskender (1999), Ansiklopedik Divan Şiiri Sözlügü̆, 6. Baskl, Ötüken, İstanbul.

ŞENÖDEYICİ, Özer (2015), "Nâ'ili Kadîm Mustafa", Türk Edebiyatı İsimler Sözlüğü, www.turkedebiyatisimlersozlugu.com

UYSAL, R. Selçuk (1997), Mûsıkî Edebiyatı, İzmir.

Temel Türkçe Sözlük ( Kâmûs-ı Türkî), (1986), C.3, Tercüman Gazetesi-Yapı Kredi Bankası Yayını, İstanbul. 
526 | Celal Bayar Üniversitesi Sosyal Bilimler Dergisi - Cilt: 14, Sayı: 1, Mart 2016 